\title{
Research of Electric Power Steering System Assistance Characteristic Based on The Identification of The Road
}

\author{
Qiang Li \\ School of Automobile and Traffic Engineering \\ Jiangsu University \\ Zhenjiang, 212013, China \\ E-mail: aydo1234liqiang@126.com
}

\author{
Changgao Xia \\ School of Automobile and Traffic Engineering, \\ Jiangsu University, \\ Zhenjiang, 212013, China \\ E-mail: xiacg@ujs.edu.cn
}

\begin{abstract}
Study of traditional assist characteristic cure does not take into account the difference of steering resistance torque caused by different road adhesion coefficient. Vehicle dynamics analysis model is established based on ADAMS/CAR. Simulation of steering wheel torque is realized under different road conditions. Departure from the ideal boost characteristics requirements and combined with ideal steering wheel torque under different speed and lateral acceleration., the article built assist characteristic curve under a certain road conditions. The system can real-time select the assist characteristic curve through identifying the vehicle traveling road conditions by the way of BP neural network. The theory provided a feasible method for the improvement of the EPS system performance.
\end{abstract}

Keywords-Electric Power Steering System; Characteristic Curve; Selection Strategy

\section{INTRODUCTION}

Assist characteristic curve is the key of the electric power steering system, it largely decides the car's steering lightweight, high-speed handling and stability, safety and road feel. Ideal power characteristic curve ensure that assistance motor should maintain idle state within a small rotate speed area of the steering wheel. With the speed of car increasing, the motor idling region should be increased in order to maintain a good road feel and keep energy conservation. Under the same car speed, assist torque increases with the increase of the steering wheel torque. And when the car turns in the zero speed and low speed, assist torque gain coefficient should be big. When the car turns in the high speed, assist torque gain coefficient should be small. In the case of the same wheel steering torque, assist torque decreases with the increase of the vehicle speed. When the vehicle speed is above a certain speed, system does not provide assist torque in order to ensure high-speed steering feel. Assist torque should be less than steering resistance to prevent the emergence of the phenomenon of "hatchet man". Each section of assist characteristic should be smooth to avoid the sense of jumping of steering torque. Therefore, assist characteristic curve often uses three types of straight-line type, broken line type and curve type. Assist torque under different vehicle speeds depends on the expectation of the driver's steering wheel torque and vehicle parameters, and then put the assist torque into corresponding motor current. But mostly assist characteristic design does not consider different road adhesion coefficient of road driving. This article started from different road adhesion coefficients and studied a broken line characteristic curve taking different road conditions into account that can better meet ideal electric power property requirements.

\section{STEERING WHEEL TORQUE OF DIFFERENT ROAD CONDITIONS WITHOUT ASSIST TORQUE}

Steering wheel torque is from the resistance moment of the tire steering. Steering resistance torque is very complex including steering resistance torque caused by wheel alignment parameters, aligning torque caused by deformation of the wheel and friction torque caused by wheel and ground. Friction torque of the wheel and the ground is decided by front wheel load, tire pressure and friction coefficient between ground and tire. In order to acquire steering wheel torque in different driving road conditions, the dynamic model of the car is established by ADAMS/CAR module. This paper got steering wheel torque through the virtual prototype simulation.

\section{A. Establishment of the whole car}

Shown in figure 1 , the virtual prototype model of the whole car is established based on ADAMS/CAR module. The model includes the front MacPherson independent suspension, rear multi-link independent suspension, rackand-pinion steering system, body, powertrain, tires and the road. The model parameters are shown in table 1.

The choice of tire is very important in the software of ADAMS/CAR. The software provides four different tires including FIALA model, UA model, SMITHERS model and DELET model and so on. The nonlinear tire is used in this paper.

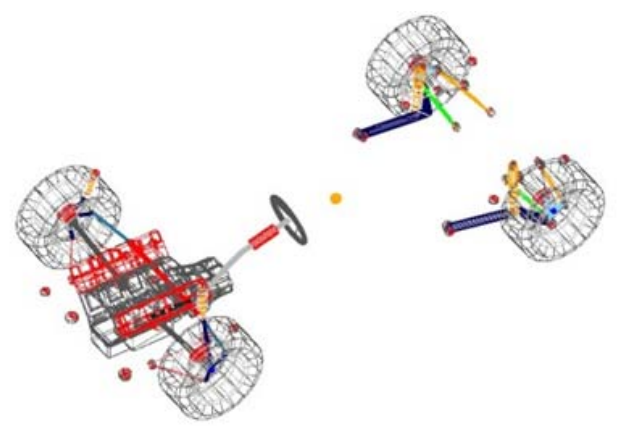

Figure 1 Vehicle dynamics model 
TABLE 1 VEHICLE TECHNICAL PARAMETERS

\begin{tabular}{|l|l|l|l|}
\hline The mass of vehicle & $1.53 \mathrm{t}$ & Tire free radius & $340.6 \mathrm{~mm}$ \\
\hline Front track & $1.52 \mathrm{~m}$ & $\begin{array}{l}\text { Tire nominal aspect } \\
\text { ratio }\end{array}$ & 0.35 \\
\hline Rear track & $1.59 \mathrm{~m}$ & $\begin{array}{l}\text { Longitudinal stiffness } \\
\text { coefficient of tire }\end{array}$ & 310 \\
\hline $\begin{array}{l}\text { Front wheel camber } \\
\text { of left and right } \\
\text { wheel }\end{array}$ & $-0.5^{\circ}$ & $\begin{array}{l}\text { Lateral stiffness of } \\
\text { tire }\end{array}$ & $190 \mathrm{~N} / \mathrm{rad}$ \\
\hline $\begin{array}{l}\text { Rear wheel camber } \\
\text { of left and right } \\
\text { wheel }\end{array}$ & $-0.5^{\circ}$ & $\begin{array}{l}\text { Longitudinal } \\
\text { damping coefficient of } \\
\text { tire }\end{array}$ & 3.1 \\
\hline $\begin{array}{l}\text { Maximum steering } \\
\text { wheel angle }\end{array}$ & $720^{\circ}$ & The width of tire & $255 \mathrm{~mm}$ \\
\hline $\begin{array}{l}\text { Maximum steering } \\
\text { wheel torque }\end{array}$ & $60 \mathrm{Nm}$ & Wheelbase & $2.56 \mathrm{~m}$ \\
\hline
\end{tabular}

B. Steering wheel torque of city traffic without power steering

ADAMS/CAR can establish a variety of road including the basic shape of the pavement and a variety of defects (such as pits, corrugated) by road model properties file, can create such as runways, parking and other complex 3D road and can fully define road center line of the three-dimensional space, the shoulders and the friction coefficient of left and right road. City road is relatively flat, without large fluctuations. ADAMS/CAR can simulate urban traffic only through a flat twodimensional road.

Vehicle speeds of $20 \mathrm{~km} / \mathrm{h}, 40 \mathrm{~km} / \mathrm{h}, 60 \mathrm{~km} / \mathrm{h}, 80 \mathrm{~km} / \mathrm{h}$, $100 \mathrm{~km} / \mathrm{h}$ are respectively set in ADAMS/CAR. Vehicle lateral acceleration starts from zero and the slope of the change with time is $0.01 \mathrm{~g} / \mathrm{s}$. The simulation time is 40 seconds. It can simulate steering wheel torque in city traffic without assist torque in the case of different vehicle speeds and different lateral accelerations. Due to change in lateral acceleration is very slow, so the simulation process ignored the steering dynamic impact on the steering wheel torque. The results are shown in figure 2 .

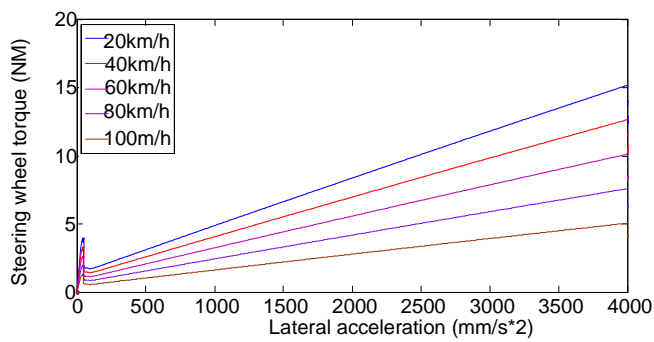

Figure 2 Curve of steering wheel torque

As can be seen from the simulation results that steering torque of the steering wheel decreases with the vehicle speed becomes high, and at a certain speed steering wheel torque increases with the vehicle lateral acceleration increases. The specific values are seen in table 2.

TABLE2 STEERING WHEEL TORQUE WITHOUT ASSIST TORQUE (NM)

TORQUE (NM)
\begin{tabular}{|l|c|c|c|c|c|}
\hline $\begin{array}{l}\text { Vetocity (km/h) } \\
\text { lateral }\end{array}$ & $\mathbf{2 0}$ & $\mathbf{4 0}$ & $\mathbf{6 0}$ & $\mathbf{8 0}$ & $\mathbf{1 0 0}$ \\
\hline
\end{tabular}

\begin{tabular}{|c|l|l|l|l|l|}
\hline acceleration & & & & & \\
\hline $\mathbf{0 . 1 g}$ & 4.9 & 4.1 & 3.3 & 2.8 & 2.7 \\
\hline $\mathbf{0 . 2 g}$ & 8.4 & 7.0 & 5.6 & 4.2 & 3.1 \\
\hline $\mathbf{0 . 3 g}$ & 12 & 9.8 & 7.8 & 5.9 & 3.9 \\
\hline $\mathbf{0 . 4 g}$ & 15 & 13 & 10 & 7.5 & 5.1 \\
\hline
\end{tabular}

C. Steering wheel torque without assist torque in rural road

There are many different points in rural roads compared to urban road. Firstly, road adhesion coefficient in the rural roads is smaller than that of the urban road. Rural road is less flat than urban road. ADAMS/CAR can change the correction of coefficient between road and tire to simulate small rural road adhesion coefficient. The paper used the C-class grade and two-dimensional random road to simulate unevenness of the rural road.

In the ADAMS/CAR, simulation conditions are set as the same as the urban roads. The results of steering wheel torque are seen in table 3.

TABLE 3 STEERING WHEEL TORQUE WITHOUT ASSIST TORQUE (NM)

\begin{tabular}{|c|l|l|l|l|l|}
\hline $\begin{array}{l}\text { Velocity (km/h) } \\
\text { lateral } \\
\text { acceleration }\end{array}$ & $\mathbf{2 0}$ & $\mathbf{4 0}$ & $\mathbf{6 0}$ & $\mathbf{8 0}$ & $\mathbf{1 0 0}$ \\
\hline $\mathbf{0 . 1 g}$ & 4.1 & 3.8 & 2.9 & 2.5 & 2.1 \\
\hline $\mathbf{0 . 2 g}$ & 7.9 & 6.7 & 5.1 & 3.9 & 2.7 \\
\hline $\mathbf{0 . 3 g}$ & 11 & 9.1 & 7.2 & 5.2 & 3.2 \\
\hline $\mathbf{0 . 4 g}$ & 13 & 12 & 9.1 & 6.8 & 4.7 \\
\hline
\end{tabular}

D. Steering wheel torque of pivot steering without assist torque

When the car turns in the speed of zero, we generally calculate the maximum moment of resistance of pivot steering by using equation 1 .

$$
T_{\max }=\frac{f}{g} \sqrt{\frac{g^{2}}{p}}(1)
$$

Where: $\tau_{\max }$-the largest steering moment of resistance of pivot steering without assist torque (NM), $f$-the coefficient of sliding friction between the tires and the road, $G_{f}$-front axle load $(N), p$-tire pressure $(P a)$.

The maximum torque of steering wheel without assist torque:

$$
T_{\text {smax }}=\frac{\tau_{\max }}{\eta_{+}}
$$

Where: $T_{\text {smax }}$-the maximum steering wheel torque provided by driver without assist torque (NM), $i$-total transmission ratio of steering system, $\eta_{+-}$-positive efficiency of steering gear.

By vehicle parameters, when car turns in the speed of zero in the urban roads, $T_{\text {max }}=18 \mathrm{NM}$.

\section{THE DETERMINATION OF ASSIST CHARACTERISTIC CURVE}

The good steering wheel force characteristic requires that the force of steering wheel should be appropriate, especially with the speed of car becomes high, the steering wheel force should not be too small to maintain a certain value. In order to give the driver with a good road 
feel, the assist characteristic curve should have the right of the steering wheel torque increases with the rate of change of the vehicle later acceleration. Therefore, when we build the assist characteristic curve, we must consider the size of force of the steering wheel input.

Aim at feature of driver steering wheel input, some research institutions at home and abroad propose the driver's average favored steering wheel ideal torque based on a lot of experiments. My driver's average favored steering wheel ideal torque is seen in table 4.

TABLE 4 DRIVER'S AVERAGE FAVORED STEERING WHEEL

\begin{tabular}{|c|c|c|c|c|c|}
\hline $\begin{array}{l}\text { Velocity }(\mathrm{km} / \mathrm{h}) \\
\text { lateral } \\
\text { acceleration }\end{array}$ & 20 & 40 & 60 & 80 & 100 \\
\hline $0.1 \mathrm{~g}$ & 1.0 & 1.7 & 2.1 & 2.3 & 2.6 \\
\hline $0.2 \mathrm{~g}$ & 1.5 & 2.0 & 2.4 & 2.8 & 3.0 \\
\hline $0.3 \mathrm{~g}$ & 1.6 & 2.3 & 2.8 & 3.1 & 3.3 \\
\hline $0.4 \mathrm{~g}$ & 1.8 & 2.4 & 2.9 & 3.3 & 3.4 \\
\hline
\end{tabular}

According to the requirements of ideal assist characteristics curve, this paper can determine the assist torque that EPS should provide in certain road conditions based on expectations of the driver's steering wheel torque and vehicle parameters.

The torque of steering wheel without assist torque subtracting the steering wheel ideal torque is the torque that EPS should provide. For the city traffic, this paper can get the torque under different speed of car and different lateral acceleration by using the date of table 2 and table 4 . The results are seen in table 5 .

Table 5 Assist torque under different speeds of car and different lateral accelerations (NM)

\begin{tabular}{|c|c|c|c|c|c|}
\hline $\begin{array}{l}\text { Velocity (km/h) } \\
\text { lateral } \\
\text { acceleration }\end{array}$ & $\mathbf{2 0}$ & $\mathbf{4 0}$ & $\mathbf{6 0}$ & $\mathbf{8 0}$ & $\mathbf{1 0 0}$ \\
\hline $\mathbf{0 . 1 g}$ & 3.9 & 2.4 & 1.2 & 0.5 & 0.1 \\
\hline $\mathbf{0 . 2 g}$ & 6.9 & 5.0 & 3.2 & 1.4 & 0.1 \\
\hline $\mathbf{0 . 3 g}$ & 11 & 7.5 & 5.0 & 2.8 & 0.6 \\
\hline $\mathbf{0 . 4 g}$ & 14 & 12 & 7.0 & 4.2 & 1.7 \\
\hline
\end{tabular}

The paper uses MTALB to conduct the polyline fitting based on ideal steering wheel torque in table 4 and the assist torque in different speed and different lateral acceleration. The results of fitting are seen in figure 3 .

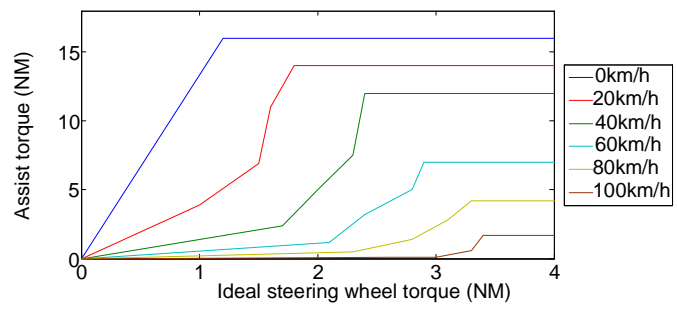

Figure 3 Assist characteristic curve of urban traffic

The figure 3 is the relational graph between assist torque and steering wheel torque when car runs in the speed of $0 \mathrm{~km} / \mathrm{h}, 20 \mathrm{~km} / \mathrm{h}, 40 \mathrm{~km} / \mathrm{h}, 60 \mathrm{~km} / \mathrm{h}, 80 \mathrm{~km} / \mathrm{h}$, $100 \mathrm{~km} / \mathrm{h}$ in city traffic. From the figure, we can calculate needed assist torque in certain vehicle speed according to ideal steering wheel torque in a traveling road conditions. When the vehicle speed is smaller, the assist gain is large to provide a big assist torque, and improve low-speed steering portability. When the vehicle speed is high, system provides a small assist torque to improve vehicle driving stability at high speed.

\section{THE SELECTION STRATEGY OF ASSIST CHARACTERISTIC CURVE}

Taking into account the vehicle traveling road, the choice of which assist characteristic curve must be considered. Therefore, the identification must be carried on the vehicle traveling road. From automotive steering conditions, this paper studies the road adhesion coefficient and identifies the road based on adhesion coefficient.

\section{A. Tire model of Dugoff}

Dugoff, non-linear tire model is used in simulation. Its parameters are seldom. There is a good expression of nonlinear tire model.

$$
\begin{aligned}
& F_{x i}=f_{1} c_{x i} S_{1} \\
& F_{y i}=f_{i} C_{y i} \alpha_{i} \text { (4) } \\
& F_{R i}=\sqrt{\left(C_{x t} S_{t}\right)^{2}+\left(C_{y t} \alpha_{t}\right)^{2}}
\end{aligned}
$$

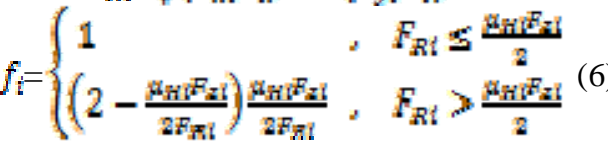

Where: $F_{\text {sei }}$-Tire longitudinal force; $F_{y t}$-Tire lateral force, $C_{y i}, C_{y i}$-The longitudinal and lateral stiffness of tire; $\alpha_{i}$-Tire slip angle, $F_{z i}$-The vertical load on the tire, $S_{i}$-Tire slip ratio, $\mu_{H t}$-Maximum road adhesion coefficient.

Each wheel slip angle:

$$
\begin{gathered}
\alpha_{f l_{f} r_{r}}=-\delta_{f}+\tan ^{-1}\left[\frac{v_{y}+r i_{f}}{v_{x \pm} \pm\left(r D_{f} g^{2}\right)}\right] \\
\alpha_{r l_{r} r}=\tan ^{-1}\left[\frac{v_{y}-r i_{f}}{v_{x \pm} \pm\left(r D_{f} g^{2}\right)}\right]
\end{gathered}
$$

Where: $\delta_{f}$-front wheel corner, $v_{x}$-tire longitudinal velocity, $v_{y}$-tire lateral speed; $r$-yaw rate, $l_{f}$-the distance between vehicle centroid and front axle, $D_{p}$-front wheel tread.

\section{B. The estimation algorithm of adhesion coefficient}

Due to nonlinearity of the tire, we do not simply use a value to estimate the state of car. The neural network algorithm has a strong ability to learn, and it can effectively deal with many nonlinear problems. Therefore, this paper uses BP neural network to predict the road adhesion coefficient as accurate as possible by learning some typical test results. This paper uses three-layer feed forward neural networks. There are input layer of four nodes: the yaw rate gain, two side slip angles of front wheels, yaw angular velocity and an output layer, the road adhesion coefficient. The hidden layer nodes of the network are determined by the experimental results of 
training learning. Figure 4 is the internal structure of the trained neural network.

\section{The selection strategy of assist characteristic curve}

For the selection of assist characteristic curve, road adhesion coefficient must be taken into account. When the road adhesion coefficient is big, the system selects assist characteristic curve of urban traffic. When the road adhesion coefficient is small, the system selects assist characteristic curve of rural traffic. Generally recognizing, road adhesion coefficient that is more than 0.7 is big and road adhesion coefficient that is less than 0.7 is small.

In the case of automotive steering, the system can predict the road adhesion coefficient by front wheel corner, the vehicle model, tire model and trained BP neural network. According to the size of road adhesion coefficient, the system selects assist characteristic curve of urban traffic and assist characteristic curve of rural traffic.

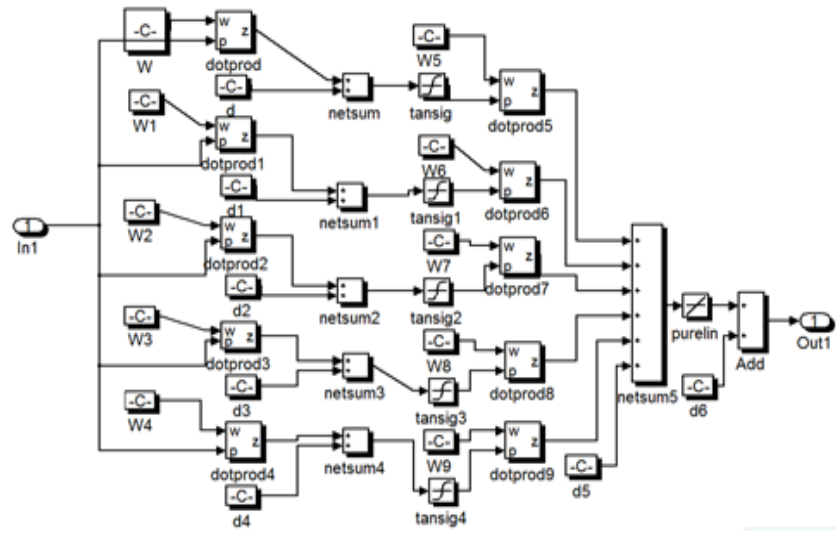

Figure 4 Internal structure of the trained BP neural network

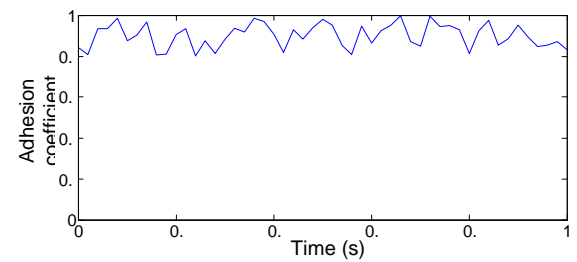

Figure 5 Simulation results of high adhesion coefficient

In AMDMS/CAR, Figure 5 is the result of simulation of car driving in urban traffic. The estimated result of road adhesion coefficient is about 0.9 , it is in a range of high road adhesion coefficient. The system selects assist characteristic curve of urban traffic according to high road adhesion coefficient.

\section{CONCLUSION}

Base on the above study, when a car turns, the system can real-time select assist characteristic curve of urban traffic or assist characteristic curve of rural traffic through the detection of road adhesion coefficient. This method can better provide appropriate assist torque according to the situation of road, vehicle speed and steering wheel torque. It effectively eases the contradiction between the steering portability and the steering feel.

Starting from different road adhesion coefficients, this paper has studied out broken line type assist characteristic curve considering the different road conditions. It can better satisfy the requirement of ideal electric assist characteristics and provides a reference for the improvement of EPS performance and follow-up study.

\section{ACKNOWLEDGMENT}

The Project Number is SBY201220101.

\section{References}

[1] Anning Chen. The EPS modeling and co-simulation. A master's degree thesis of Jiangsu University. [D].2008

[2] Li Li. Steering torque characteristics analysis and research of EPS power control strategy. A master's degree thesis of Tongji University. [D].2006

[3] Jiarui Chen. Automobile structure [M].Beijing : People' s communications press.

[4] Jun Chen. MSC.ADAMS Technology and engineering analysis instance. Beijing : China water power press [M], 2008.10

[5] Pei Zhu. Characteristic Analysis and Test Research on ElectroHydraulic Power Steering System. A master's degree thesis of Jiangsu University. [D].201005.

[6] Xiangyu Liu. Study of vehicle stability control system based on direct yaw moment control. A doctor's degree thesis of Hefei University. [D].201010

[7] Xin Zhou. Co-simulation of car electric power steering system based on ADAMS and MATLAB. A master's degree thesis of Jiangsu University. [D].200905 